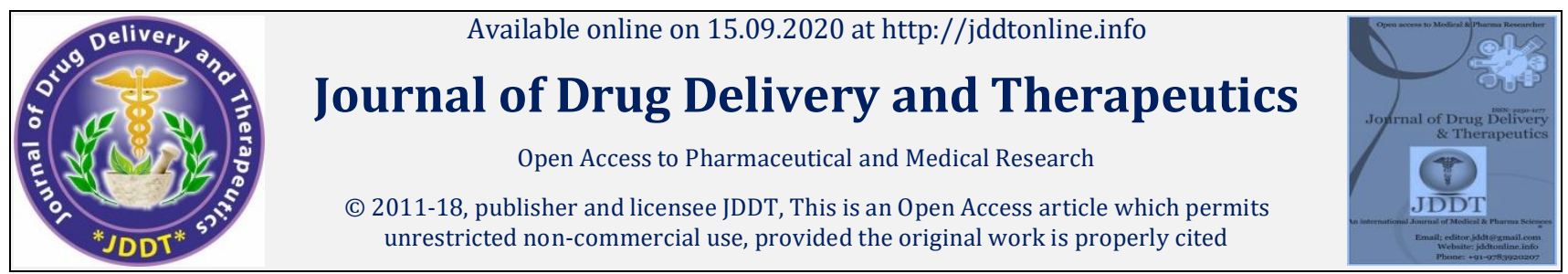

Open 1 Access

Research Article

\title{
Evaluation of Phytocompounds and Chemical Elements Present In Selected Species of Seaweeds, to Sustain Future Quantitative Analysis for Bioactive Compounds
}

\author{
Valera Diass $^{1 *}$, Salomão Bandeira ${ }^{1}$, Eutilério Chaúque ${ }^{2}$, Maurício Lipassula ${ }^{1}$, Aidate Mussagy ${ }^{1}$ \\ ${ }^{1}$ Department of Biological Sciences, Eduardo Mondlane University, Maputo, Mozambique \\ ${ }^{2}$ Department of Chemistry, Eduardo Mondlane University, Maputo, Mozambique
}

\begin{abstract}
Introduction: The specific physiological capacity of marine organisms, including seaweeds, to survive in extreme environmental conditions is associated to the production of secondary metabolites. Seaweeds are known as powerful source of a broad range of bioactive compounds. Objective: The aim of this study was to investigate the phytocompounds and chemical elements present in eight species of seaweeds which occur around Inhaca Island, Mozambique. Specifically, Halimeda cuneata, Pseudorhizoclonium africanum, Pseudocodium devriesii, Dictyota suhrii, Gracilaria salicornia, Hypnea rosea, Laurencia natalensis and Jania adhaerens. Methods: For phytocompounds and chemical elements screening, seaweeds samples were dried, ground to powder and extracted using methanol as solvent. The analyses were performed using GC-MS analysis, Energy Dispersive X-ray Fluorescence, and colorimetric protocols for phytocompound analysis. Results: A total of 82 phytocompounds were identified. Phytol and Z-8-Methyl-9-tetradecenoic were present in all samples analysed, while Cetene, 9-0ctadecenoic acid (Z)-methyl ester, Desmoterol, Octadecanoic acid, and Oleic acid were the less common phytocompound identified. Campesterol, gama-Sitoesterol, Cholest-5-enol, 24-propylidene-(3.beta) are phytosterols only identified in green seaweeds. The concentration of chemical elements among the seaweeds species was different. However, $\mathrm{Ca}, \mathrm{Cl}$ and $\mathrm{K}$ were presented in high concentration in some of the seaweeds analysed. Conclusion: Overall, the seaweeds analysed in this study, seems to be good candidate for further biotechnological application and deserve further investigation.
\end{abstract}

Keywords: seaweeds, methanolic extracts, phytocompounds, minerals, Inhaca Island.

Article Info: Received 21 July 2020; Review Completed 26 August 2020; Accepted 05 Sep 2020; Available online 15 Sep 2020

Cite this article as:

Dias V, Bandeira S, Chaúque E, Lipassula M, Mussagy A, Evaluation of Phytocompounds and Chemical Elements Present In Selected Species of Seaweeds, to Sustain Future Quantitative Analysis for Bioactive Compounds, Journal of Drug Delivery and Therapeutics. 2020; 10(5):232-239 http://dx.doi.org/10.22270/jddt.v10i5.4422

*Address for Correspondence:

Valera Dias, Eduardo Mondlane University, Department of Biological Sciences, P0 Box 257, Maputo, Mozambique

\section{INTRODUCTION}

In recent years, marine resources have been tested to find potential compounds for the development of products with different applications, as they are a rich source of novel biocompounds ${ }^{1,2}$. In fact, the specific physiological capabilities of marine organisms, allow them to survive in extreme conditions and, provide a great potential for production of secondary metabolites compared to common organisms in terrestrial environments ${ }^{3}$. Among the marine resources investigated so far, seaweeds or marine macroalgae are known as rich in a broad range of compounds ${ }^{4}$, and researchers suggest them as a promising resource to provide novel biochemically active substances 5,6 . Biocompounds from seaweeds can be used as natural products in different industry such as pharmaceuticals, cosmetic, human nutrition, animal feed, fertilizer and bioplastics production 7 . These industries mainly search for antioxidants, antimicrobial, anti-parasitic, anti-inflammatory, antiallergic, antifeedant, anti-trombic, anticarcenogenic and anti-ulcer 8,9 . The seaweeds metabolites with biological interest include alkaloids, phenols, flavonoids, saponins, steroids, and terpenoids $\mathrm{s}^{9,10}$, and the techniques used to their extraction have been intensively reviewed 4 . Among the different procedures to analyse seaweeds metabolites, methanolic extracts was found to have the highest reducing power in comparison with other solvents such as chloroform, acetone and ethanol ${ }^{2}$. However, results are controversy among different studies and seem to be species specific ${ }^{4}$.

Despite the broad application of seaweed extracts worldwide ${ }^{11-13}$, in Mozambique where nearly 300 species of seaweeds have been registered these resources are under exploited ${ }^{14}$. To the best of our knowledge there is no scientific information in Mozambique reporting the phytochemical characterization and application of seaweeds 
metabolites. Therefore, the purpose of the present study was to carry out a preliminary screening to investigate the phytocompounds and chemical elements present in eight species of seaweeds which occur around Inhaca Island, southern Mozambique. Specifically, the study evaluated the presence of phytocompounds and chemical elements in three species of Chlorophyta, Halimeda cuneata Hering, Pseudocodium devriesii Weber Bosse and Pseudorhizoclonium africanum (Kützing) Boedeker; one species of Phaeophyta, Dictyota suhrii G. Murray and four species of Rhodophyta Gracilaria salicornia (C. Agardh) E.Y. Dawson, Hypnea rosea Papenfuss, Laurencia natalensis Kylin and Jania adhaerens J.V. Lamouroux. All these species were previously described for Mozambique with exception to $D$ suhrii until recently known only to KwaZulu/Natal in South Africa ${ }^{15}$. These species were chosen due to the availability and group diversity along Mozambican coast. Mozambique seaweed flora is still poorly studied 16 , the country having quite a handful of papers highlighting to Inhaca16,17, XaiXai18, Mozambique Island19, Mecúfi20 and Quirimbas archipelago ${ }^{21}$. The results of the present study might open to new opportunities and venues of research and development on seaweeds exploitation and brings solution to the gaps of our understanding of valuable seaweeds in Mozambique and the Western Indian Ocean region.

\section{MATERIALS AND METHODS}

\section{Collection of seaweeds}

This study consisted of sampling of target species of seaweeds in Inhaca Island, and further laboratorial analysis of chemical elements and phytochemical compounds composition. The seaweed sampling was carried in October of 2018 at Ponta Mazónduè (near Farol) in Inhaca Island, in intertidal zone, during low spring tide. The north-eastern region of the island presents dense seaweed vegetation which extensive tracts are exposed during the low tidal range $^{22}$. Eight species of seaweeds were sampled, specifically: three species of Chlorophyta, $H$. cuneata Hering $P$. africanum and $P$. devriesii Weber Bosse; one species of Phaeophyta, D. suhrii and four species of Rhodophyta, $G$. salicornia (C.Agardh) E.Y.Dawson, H. rosea Papenfuss, $L$. natalensis Kylin and J. adhaerens J.V. Lamouroux. For Identification, books and field guide for seaweeds were used 15-23, and their voucher specimens kept at the LMU herbarium at the Department of Biological Science, Eduardo Mondlane University.

Approximately $200 \mathrm{~g}$ of the seaweed were hand-picked, and a knife was used to remove de seaweed when necessary. The samples were transported in a basket with seawater, to avoid drying, to the Eduardo Mondlane University's laboratory. In the laboratory, the samples were cleaned to remove epiphytes, necrotic parts, and rinsed with distilled water to remove salts, sand particles and any associated detritus. Next, the samples were oven dried at $50{ }^{\circ} \mathrm{C}$ for 72 hours, and ground in an electric mixer, the powdered samples were weighed, and stored in a cool dry place until further analyses.

\section{Identification of phytocompounds using Gas chromatography-mass spectrometry (GC-MS) analysis}

The analyses of phytochemical compounds followed an adapted $^{24}$ procedure. Briefly, each powered seaweeds sample was weighted, transferred to flask, treated with the Methanol until the powder was fully immersed, incubated overnight and filtered through a Whatmann filterpaper along with Sodium sulphate was wetted with absolute alcohol. The filtrates were then concentrated to $1 \mathrm{ml}$ by bubbling nitrogen gas in to the solution. The extract contains both polar and non-polar components of the material and 2 $\mu \mathrm{l}$ sample of the solution was employed in GC-MS for analysis of different compounds. The GC - MS analysis was carried out using a Agilent 7820A GC System Gas Chromatograph equipped and coupled to a mass detector Turbo mass gold, column - 5 MS 30 m (length) $250 \mu \mathrm{m}$ (inner diameter) $0.25 \mu \mathrm{m}$ (film). The instrument was set to an initial temperature of $110{ }^{\circ} \mathrm{C}$, and maintained at this temperature for $2 \mathrm{~min}$. At the end of this period the oven temperature was rose up to $280^{\circ} \mathrm{C}$, at the rate of an increase of $5 \mathrm{o} \mathrm{C} / \mathrm{min}$, and maintained for $9 \mathrm{~min}$. Injection port temperature was ensured as $250{ }^{\circ} \mathrm{C}$ and Helium flow rate as one $\mathrm{ml} / \mathrm{min}$. The ionization voltage was $70 \mathrm{eV}$. The samples were injected in split mode as 10:1. Mass spectral scan range was set at 45-450 (m/z). Interpretation on Mass-Spectrum GC-MS was conducted using the database of National Institute Standard and Technology (NIST) 2014, having more 62,000 patterns. The spectrum of the unknown components was compared with the spectrum of known components stored in the NIST 2014 library. The name, molecular weight and structure of the components of the test materials were ascertained. The compounds identified in this study are limited to the volatile and volatilizable compounds, which must be capable to retain in the column used; additionally, the components responsible for the observed peaks must be included in the library database.

\section{Concentration of chemical elements in seaweed samples}

An amount of $5 \mathrm{~g}$ of each seaweeds powder were used to assess the semi-quantitative concentrations of the most frequent chemical elements by the methods of X-ray fluorescence scanning (Energy Dispersive X-ray Fluorescence, EDXRF, Shimadzu 7000, Japan). This is a relatively effective qualitative and semi-quantitative technique to analyse major, minor and trace elements 25,26 . Basically, the semi-quantitative analysis of elements was done at an accelerating voltage of $50 \mathrm{kV}, 30 \mathrm{~A}$, and at a detection time of $280 \mathrm{~s}$ with a Shimadzu EDX-700. The elements' concentrations were expressed as a percentage of their relative atomic abundances.

\section{Qualitative analysis of secondary metabolic compounds}

Standard colorimetric method was used for qualitative analysis of phenolic compounds. Methanolic extracts were prepared for each seaweed sample. An amount of $2 \mathrm{~g}$ of sample were extracted with $40 \mathrm{ml}$ of methanol for 90 minutes and concentrated on a rotavapor up to $10 \mathrm{ml}$ at 60 ${ }^{\circ} \mathrm{C}$. The phytochemical screening of different algal extracts was assessed using standard method as described ${ }^{27}$. Phytochemical screening was carried out to identify the major natural chemical groups such as alkaloids, terpenoids, steroids, tannins, saponins, flavonoids, phenols, coumarins, quinones and glycosides.

Test of coumarins (NaOH test): $1 \mathrm{~mL}$ of each methanolic extract was added to a test tube containing $1 \mathrm{~mL}$ of $10 \%$ $\mathrm{NaOH}$ and the appearance of a yellow colour indicated the presence of coumarins 27 .

Test of tannins ( FeCl $_{3}$ test): $1 \mathrm{~mL}$ of each methanolic extract was added to a test tube containing $1 \mathrm{~mL}$ of $5 \% \mathrm{FeCl}_{3}$ and the appearance of a blue colour indicated the presence of hydrolyzable tannins and the appearance of a green colour indicated the presence of condensed tannins ${ }^{27}$.

Test of Flavonoids: $1 \mathrm{~mL}$ of each methanolic extract was added to a test tube containing $1 \mathrm{~mL}$ of chloroform and $1 \mathrm{~mL}$ of $1 \% \mathrm{NH}_{4} \mathrm{OH}$ was added, and the appearance of a yellow color in the ammonia layer indicated the presence of flavonoids. The subclasses of flavonoids were identified as follows: 
Flavonols (Shinoda test): $1 \mathrm{~mL}$ of each methanolic extract was added to a test tube containing a piece of magnesium tape (about $1 \mathrm{~cm}$ ) and 2-3 drops of $32 \% \mathrm{HCl}$ were placed. The appearance of an orange colour indicated the presence of flavones and the appearance of a red colour indicated the presence of flavonols ${ }^{27}$.

Flavanones (NaOH test): $1 \mathrm{~mL}$ of each methanolic extract was added to a test tube containing $1 \mathrm{~mL}$ of $10 \% \mathrm{NaOH}$ and the appearance of a yellow to orange colour indicated the presence of flavanones 27 .

Test of saponin (foam test): $1 \mathrm{~mL}$ of each extract methanolic extract was added to a test tube containing $1 \mathrm{~mL}$ of distilled water and stirred permanently for 3 minutes. Persistent foaming for more than 5 minutes indicated the presence of saponins ${ }^{27}$.

Test of alkaloids (Mayer test): $1 \mathrm{ml}$ of each methanolic extract was added to a test tube containing 6-12 drops of $2 \%$ $\mathrm{HCl}$ and filtered. To the filtrate, 2-3 drops of Mayer's reagent were added and the appearance of a yellow precipitate colour indicated the presence of alkaloids ${ }^{27}$.

Test of steroid (Liebermann-Burchard test): $1 \mathrm{~mL}$ of each methanolic extract was added to a test tube containing about 10 drops of anhydrous acetic acid and then 2-3 drops of concentrated sulfuric acid were added. The colour change from blue to green indicated the presence of steroids ${ }^{27}$.

\section{RESULTS AND DISCUSSION}

Seaweeds are potential sources of novel bioactive compounds which might bring new insights to industries such as pharmacology, animal feed, cosmetics, and others ${ }^{9}$. This study allowed to identify 82 phytocompounds from methanolic extract of eight seaweeds species (Table 1), by applying GC-MS, a high sensitive equipment which allow to identify volatile molecules from the samples 28 ; being also the most precise methods to identify various phytocompounds in extracts from different species ${ }^{29}$. From the extracts analysed in this study, J. adhaerens and P. devriesii are the species with more phytocompounds identified, 36 and 33, respectively, these findings might indicate that these species are rich in the phytocompounds. According to Domettila et al. 30 , the seaweeds with a range of secondary metabolites might be strong candidates to be applied in pharmacy technology.

Among the species of seaweeds, the more frequent phytocompounds identified were n-Hexadecanoic acid, Cholesterol, Phytol, Phytol acetate, cis-13-Eicosenoic acid, Tetradecanoic acid, and Z-8-Methyl-9-tetradecenoic acid. Particularly, Phytol and Z-8-Methyl-9-tetradecenoic were found to be commonly present in all of the extracts analysed. However, n-Hexadecanoic acid was detected in the methanol blank sample. Therefore, it was not a surprised that it appeared in all samples. Phytol is a common compound found in plants and seaweeds. It is a key acyclic diterpene alcohol that is a precursor for vitamins $\mathrm{E}$ and $\mathrm{K}^{31}$. In other studies, it was reported to have antibacterial activities against Staphylococcous aureus and antifungical activities against Ganoderma boninense ${ }^{32}$.

On the other hand, some compounds were detected in only one species of seaweed in this study, which include Cetene (U. adhaerens), Desmosterol (D. suhrii) and Oleic acid (P. africanum). From these three compounds, Cetene (also known as 1-Hexadecene) was intensively reported in extract of plants such as Citrus limon ${ }^{33}$, Gleichenia pectinata ${ }^{34}$ and
Hyptis verticillata ${ }^{35}$. Kebelmann et al. ${ }^{36}$ reported that Cetene where detected only in three species of polar seaweeds (Monostroma arcticum, Sphacelaria plumose and Kallymenia antarctica), out of thirteen species evaluated. In a study performed in fungus Berkleasmium sp. Dzf12, Mou et al. ${ }^{37}$ reported that Cetene showed antimicrobial and antioxidant effects.

Campesterol, Linoleic acid ethyl ester, gama-Sitoesterol, Cholest-5-en-ol - 24-propylidene-(3.beta) are all phytosterols only found in $H$. cuneata, $P$. devriesii (both Chlorophyta). Phytosterols are metabolites synthesized by plant and algae, with great relevance to the development of new drugs and functional foods. According to Ogbe et al.38 phytosterols may promote the health of humans and animals when they are included in their diet as natural foods or in enriched food supplements, for a regular period. These compounds are benefic, probably, due to their ability to lower cholesterol levels ${ }^{39}$. Campesterol, in particular, showed to have chemo-preventive effects against different types of cancer ${ }^{40}$, and this phytocompound was reported in Dictyota dichotoma and Sargassum granuliferum ${ }^{41}$ and several other species of Phaeophyta from Antarctica ${ }^{42}$.

The qualitative colorimetric methods, used to evaluate some groups of phytocompounds (Table 2), revealed that condensed tannins and alkaloids were present in most of methanolic extracts, analysed in the present study. Tannins were similarly obtained in methanolic extracts in different studies, such as the ones with the brown seaweeds $D$. dichotoma ${ }^{27}$ and Sargassum wightii ${ }^{10}$; red seaweeds Jania rubens, Corallina mediterranea and Pterocladia capillacea ${ }^{2}$; and in green seaweed Cladophora glomerata, Ulva lactuca and Ulva reticulata ${ }^{10}$; the obtained results suggest that tannins are common phytocompounds in seaweeds. In terms of application, Tannin-containing drugs are used as astringent, as healing agents in inflammation, gonorrhea, and seems to have antiviral, antibacterial and antiulcer activity ${ }^{9}$. Looking at alkaloids, some studies reported that these compounds were present in extracts of $D$. dichotoma ${ }^{27}$, in J. rubens, C. mediterranea and P. capillacea ${ }^{2}$, but it was absent in all species analysed by Abirami and Kowsalya ${ }^{24}$ and by Mansuya et al.10. This phytocompound was mentioned to inhibit the growth of both Gram-positive and Gram-negative bacteria ${ }^{43}$.

In this study, the test for saponins and steroids were positive only in the methanolic extracts of two species of Chlorophyta (H. cuneata and P. devriesii). However, in other studies these two phytocompounds were detected in $S$. wrightii ${ }^{9}$ and $D$. dichotoma ${ }^{27}$, which are both Phaeophyta. Mansuya et al.10 detected these two phytocompounds in all six species analysed. Saponins present diverse biological characteristics such as antimicrobial, anti-inflammatory, anti-feedent and hemolytic effects ${ }^{44}$, while steroids are reported to have an important role in nutrition, cosmetics ${ }^{27}$ and especially in medicine ${ }^{45}$.

The test for coumarins was positive only in two Rhodophyta species ( $G$. salicornia and $H$. rosea). Although tests for coumarins revealed positive in species of Rhodophyta - by El-Din and Al-Ahwany ${ }^{2}$ - in methanolic extract of J. rubens, $C$. mediterranea and $P$. capillacea, in the present study it revealed negative in methanolic extract of J. adhaerens and $L$. natalensis, which are also Rhodophyta. These results might indicate that these phytocompounds are specific to some species of Rhodophyta. In terms of application, coumarins are known as anti-coagulant to treat lymphedema ${ }^{46}$. 
Table 1: Chemical composition of methanolic extracts of eight species of seaweeds analysed using GC-MS. Chloro-Chlorophyta, Phaeo-Phaeophyta, Rhodo-Rhodophyta.

\begin{tabular}{|c|c|c|c|c|c|c|c|c|c|}
\hline \multirow{2}{*}{\multicolumn{2}{|c|}{ Name of the compound }} & \multicolumn{3}{|c|}{ Chloro. } & \multirow{2}{*}{ 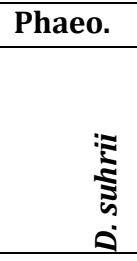 } & \multicolumn{4}{|c|}{ Rhodo. } \\
\hline & & 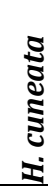 & 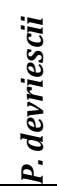 & 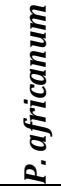 & & 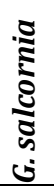 & 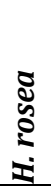 & 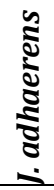 & 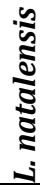 \\
\hline 1 & $\begin{array}{l}{[1,1 \text { '-Bicyclopropyl]-2-octanoic acid, 2'-he1yl-, }} \\
\text { methyl ester }\end{array}$ & & & & & & & & $\mathbf{x}$ \\
\hline 2 & 11-Octadecenoic acid, methyl ester & $\mathbf{x}$ & $\mathbf{x}$ & $\mathbf{x}$ & & & $\mathbf{x}$ & & \\
\hline 3 & 12,15-Octadecadiynoic acid, methyl ester & & & & & & & $\mathbf{x}$ & \\
\hline 4 & 12-Methyl-E,E-2,13-octadecadien-1-ol & & & $\mathbf{x}$ & & & & & \\
\hline 5 & 15-Tetracosenoic acid, methyl ester, (Z)- & & $\mathbf{x}$ & & & & & & \\
\hline 6 & 17-Octadecynoic acid & & & $\mathbf{x}$ & & & & & \\
\hline 7 & 1-Heptatriacotanol & $\mathbf{x}$ & $\mathbf{x}$ & $\mathbf{x}$ & $\mathbf{x}$ & & & & \\
\hline 8 & 1-He1adecanol, 2-methyl & & & & & & & $\mathbf{x}$ & \\
\hline 9 & 2-Pentadecanone, 6,10,14-trimethyl- & & & $\mathbf{x}$ & $\mathbf{x}$ & & & $\mathbf{x}$ & \\
\hline 10 & 3,7,11,15-Tetramethyl-2-he1adecen-1-ol & $\mathbf{x}$ & $\mathbf{x}$ & & & & & & \\
\hline 11 & 5,8,11,14-Eicosatetraenoic acid, methyl ester, (allZ)- & & & & & $\mathbf{x}$ & & $\mathbf{x}$ & \\
\hline 12 & $\begin{array}{l}\text { 6-Hydro1y-4,4,7a-trimethyl- } \\
\text { 5,6,7,7atetrahydrobenzofuran-2(4H)-one }\end{array}$ & & & & $\mathbf{x}$ & $\mathbf{x}$ & & $\mathbf{x}$ & $\mathbf{x}$ \\
\hline 13 & 6-Octadecenoic acid, methyl ester, (Z) & & & & & $\mathbf{x}$ & & & $\mathbf{x}$ \\
\hline 14 & 7,10-He1adecadienoic acid, methyl ester & $\mathbf{x}$ & $\mathbf{x}$ & $\mathbf{x}$ & & $\mathbf{x}$ & & $\mathbf{x}$ & $\mathbf{x}$ \\
\hline 15 & $\begin{array}{l}\text { 7-01abicyclo[4.1.0]heptane, 1-methyl-4- } \\
\text { (2methylo1iranyl)- }\end{array}$ & & & & & & & $\mathbf{x}$ & \\
\hline 16 & 8,11,14-Eicosatrienoic acid, (Z,Z,Z)- & $\mathbf{x}$ & & $\mathbf{x}$ & & & & $\mathbf{x}$ & \\
\hline 17 & 9,12,15-Octadecatrienoic acid, (Z,Z,Z)- & & $\mathbf{x}$ & $\mathbf{x}$ & & & & & \\
\hline 18 & 9,12-Octadecadienoic acid (Z,Z)-, methyl ester & $\mathbf{x}$ & $\mathbf{x}$ & $\mathbf{x}$ & & & & & $\mathbf{x}$ \\
\hline 19 & 9,12-Octadecadienoyl chloride, (Z,Z)- & $\mathbf{x}$ & $\mathbf{x}$ & & & & & & \\
\hline 20 & 9-He1adecenoic acid, methyl ester, (Z)- & $\mathbf{x}$ & & & & & & & \\
\hline 21 & 9-Nonadecene & & & $\mathbf{x}$ & & & & & \\
\hline 22 & 9-Octadecenoic acid (Z)-, methylester & & & & $\mathbf{x}$ & & & $\mathbf{x}$ & \\
\hline 23 & alpha.-Terpineol & & & & & & & $\mathbf{x}$ & \\
\hline 24 & Arginine & & & & $\mathbf{x}$ & $\mathbf{x}$ & & & $\mathbf{x}$ \\
\hline 25 & $\begin{array}{l}\text { Benzenepropanoic acid, 3,5-bis(1,1dimethylethyl)-4- } \\
\text { hydro1y-, methyl ester }\end{array}$ & & & & $\mathbf{x}$ & $\mathbf{x}$ & & $\mathbf{x}$ & $\mathbf{x}$ \\
\hline 26 & beta.-D-Glucopyranose, 4-0-.beta.-Dgalactopyranosyl & & & & $\mathbf{x}$ & & & & \\
\hline 27 & Campesterol & $\mathbf{x}$ & $\mathbf{x}$ & & & & & & \\
\hline 28 & Cetene & & & & & & & $\mathbf{x}$ & \\
\hline 29 & Cholest-5-en-3-ol, 24-propylidene-, (3.beta.) & $\mathbf{x}$ & $\mathbf{x}$ & & & & & & \\
\hline 30 & Cholesterol & $\mathbf{x}$ & $\mathbf{x}$ & $\mathbf{x}$ & $\mathbf{x}$ & $\mathbf{x}$ & $\mathbf{x}$ & $\mathbf{x}$ & \\
\hline 31 & cis-13-Eicosenoic acid & & $\mathbf{x}$ & & & & & & \\
\hline 32 & cis-5,8,11,14,17-Eicosapentaenoic acid & $\mathbf{x}$ & & & & & & & \\
\hline 33 & cis-Vaccenic acid & & & & $\mathbf{x}$ & $\mathbf{x}$ & $\mathbf{x}$ & & \\
\hline 34 & Cyclododecane & & & & & & & $\mathbf{x}$ & \\
\hline 35 & Desmosterol & & & & $\mathbf{x}$ & & & & \\
\hline 36 & Dodecanoic acid, 3-hydro1y- & & & & $\mathbf{x}$ & $\mathbf{x}$ & & & \\
\hline 37 & E-15-Heptadecenal & & & & $\mathbf{x}$ & & & $\mathbf{x}$ & \\
\hline 38 & E-2-Tetradecen-1-ol & & $\mathbf{x}$ & & & & & & \\
\hline 39 & Eicosatetraenoic acid, methyl ester, (allZ)- & & $\mathbf{x}$ & $\mathbf{x}$ & & $\mathbf{x}$ & & & $\mathbf{x}$ \\
\hline 40 & Ergosta-5,22-dien-3-ol, (3.beta.,22E,24S) & & & & $\mathbf{x}$ & & & & \\
\hline 41 & Ethyl Oleate & $\mathbf{x}$ & $\mathbf{x}$ & & & & & & \\
\hline 42 & 3-Eicosene, (E) & & & & & & & $\mathbf{x}$ & \\
\hline 43 & exo-2,7,7-trimethylbicyclo[2.2.1]heptan-2-ol & $\mathbf{x}$ & & & & & & $\mathbf{x}$ & \\
\hline 44 & gamma.-Linolenic acid, methyl ester & & $\mathbf{x}$ & & & & & & \\
\hline 45 & gamma.-Sitosterol & $\mathbf{x}$ & $\mathbf{x}$ & & & & & & \\
\hline
\end{tabular}


Table 1. (continued)

\begin{tabular}{|c|c|c|c|c|c|c|c|c|c|}
\hline \multirow{2}{*}{\multicolumn{2}{|c|}{$\begin{array}{r}\text { Name of the compound } \\
\end{array}$}} & \multicolumn{3}{|c|}{ Chloro. } & Phaeo. & \multicolumn{4}{|c|}{ Rhodo. } \\
\hline & & 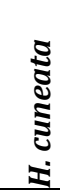 & 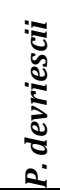 & 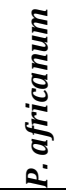 & 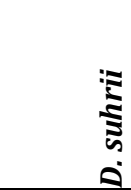 & 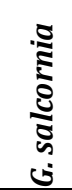 & 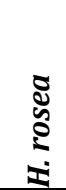 & 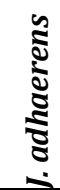 & 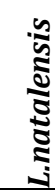 \\
\hline 46 & Geranyl vinyl ether & & & & & & & & $\mathbf{x}$ \\
\hline 47 & Glycerol 1-palmitate & & & & & & $\mathbf{x}$ & & \\
\hline 48 & Heptadecane & $\mathbf{x}$ & & $\mathbf{x}$ & $\mathbf{x}$ & & & $\mathbf{x}$ & $\mathbf{x}$ \\
\hline 49 & Heptadecanoic acid, 10-methyl-, methyl ester & & & & & $\mathbf{x}$ & & $\mathbf{x}$ & $\mathbf{x}$ \\
\hline 50 & He1adecanoic acid, 2-hydro1y- & & & & & $\mathbf{x}$ & & & \\
\hline & 1(hydro1ymethyl)ethyl ester & & & & & & & & \\
\hline 51 & He1adecanoic acid, methyl ester & & $\mathbf{x}$ & $\mathbf{x}$ & $\mathbf{x}$ & & $\mathbf{x}$ & $\mathbf{x}$ & $\mathbf{x}$ \\
\hline 52 & Imidazole, 2-amino-5-[(2-carbo1y)vinyl]- & & & & & & & $\mathbf{x}$ & $\mathbf{x}$ \\
\hline 53 & Isopropyl palmitate & & & & & & & & $\mathbf{x}$ \\
\hline 54 & l-Gala-l-ido-octose & & & & & $\mathbf{x}$ & & & \\
\hline 55 & Linoleic acid ethyl ester & $\mathbf{x}$ & $\mathbf{x}$ & & & & & & \\
\hline 56 & Methyl stearate & & $\mathbf{x}$ & & & & & & \\
\hline 57 & Methyl tetradecanoate & $\mathbf{x}$ & $\mathbf{x}$ & & & & & $\mathbf{x}$ & \\
\hline 58 & Neophytadiene & & $\mathbf{x}$ & $\mathbf{x}$ & & & & $\mathbf{x}$ & \\
\hline 59 & n-He1adecanoic acid & $\mathbf{x}$ & $\mathbf{x}$ & $\mathbf{x}$ & $\mathbf{x}$ & $\mathbf{x}$ & $\mathbf{x}$ & & $\mathbf{x}$ \\
\hline 60 & Octadecanoic acid & & & & $\mathbf{x}$ & & & & \\
\hline 61 & Oleic Acid & & & $\mathbf{x}$ & & & & & \\
\hline 62 & Palmitoleic acid & $\mathbf{x}$ & & & & $\mathbf{x}$ & $\mathbf{x}$ & & \\
\hline 63 & Pentadecanoic acid & & & & $\mathbf{x}$ & $\mathbf{x}$ & & $\mathbf{x}$ & \\
\hline 64 & Phthalic acid, butyl undecyl ester & & & & & & & $\mathbf{x}$ & \\
\hline 65 & Phthalic acid, di(2-propylpentyl) ester & $\mathbf{x}$ & $\mathbf{x}$ & & & & & & \\
\hline 66 & Phytol & $\mathbf{x}$ & $\mathbf{x}$ & $\mathbf{x}$ & $\mathbf{x}$ & $\mathbf{x}$ & $\mathbf{x}$ & $\mathbf{x}$ & $\mathbf{x}$ \\
\hline 67 & Phytol, acetate & & $\mathbf{x}$ & $\mathbf{x}$ & $\mathbf{x}$ & $\mathbf{x}$ & $\mathbf{x}$ & $\mathbf{x}$ & $\mathbf{x}$ \\
\hline 68 & Pterin-6-carbo1ylic acid & & $\mathbf{x}$ & & & & & $\mathbf{x}$ & $\mathbf{x}$ \\
\hline 69 & R-Limonene & & & & & $\mathbf{x}$ & & & $\mathbf{x}$ \\
\hline 70 & Stigmastan-3,5-diene & $\mathbf{x}$ & & $\mathbf{x}$ & & & & & \\
\hline 71 & Tetracosanoic acid, methyl ester & $\mathbf{x}$ & & $\mathbf{x}$ & & & & & $\mathbf{x}$ \\
\hline 72 & Tetradecane, 2,6,10-trimethyl- & & $\mathbf{x}$ & $\mathbf{x}$ & & & & & \\
\hline 73 & Tetradecanoic acid & $\mathbf{x}$ & $\mathbf{x}$ & $\mathbf{x}$ & $\mathbf{x}$ & $\mathbf{x}$ & $\mathbf{x}$ & $\mathbf{x}$ & $\mathbf{x}$ \\
\hline 74 & Tetradecanoic acid, 12-methyl-, methyl ester & & & & & & & $\mathbf{x}$ & \\
\hline 75 & trans-13-Octadecenoic acid & & & & & $\mathbf{x}$ & & $\mathbf{x}$ & \\
\hline 76 & Trichloroacetic acid, he1adecyl ester & & & & & & & $\mathbf{x}$ & \\
\hline 77 & Undec-10-ynoic acid, dodecyl ester & $\mathbf{x}$ & $\mathbf{x}$ & & & & & $\mathbf{x}$ & \\
\hline 78 & Z-(13,14-Epo1y)tetradec-11-en-1-ol acetate & & $\mathbf{x}$ & $\mathbf{x}$ & & $\mathbf{x}$ & & & \\
\hline 79 & Z,Z-2,5-Pentadecadien-1-ol & & & & & & & $\mathbf{x}$ & \\
\hline 80 & Z-10-Tetradecen-1-ol acetate & & & & $\mathbf{x}$ & $\mathbf{x}$ & & $\mathbf{x}$ & $\mathbf{x}$ \\
\hline 81 & Z-5-Nonadecene & $\mathbf{x}$ & $\mathbf{x}$ & $\mathbf{x}$ & & & & & \\
\hline 82 & Z-8-Methyl-9-tetradecenoic acid & $\mathbf{x}$ & $\mathbf{x}$ & $\mathbf{x}$ & $\mathbf{x}$ & $\mathbf{x}$ & $\mathbf{x}$ & $\mathbf{x}$ & $\mathbf{x}$ \\
\hline
\end{tabular}

Table 2: Qualitative description of phytochemical compounds in methanolic extracts of eight species of seaweeds, collected in Inhaca Island. Chloro-Chlorophyta, Phaeo-Phaeophyta, Rhodo-Rhodophyta.

\begin{tabular}{|c|c|c|c|c|c|c|c|c|c|}
\hline \multirow{2}{*}{\multicolumn{2}{|c|}{ Phytocompounds }} & \multicolumn{3}{|c|}{ Chloro. } & \multirow{2}{*}{ Phaeo. } & \multicolumn{4}{|c|}{ Rhodo. } \\
\hline & & 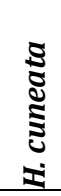 & 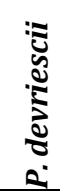 & 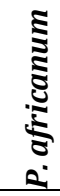 & & 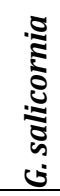 & 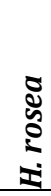 & $\begin{array}{l}\frac{y}{5} \\
\frac{5}{ \pm} \\
\frac{5}{5} \\
\end{array}$ & 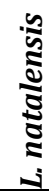 \\
\hline 1 & Condensed tannins & + & + & + & + & - & + & + & + \\
\hline 2 & Hydrolyzable tannins & - & - & - & - & - & - & - & - \\
\hline 3 & Coumarinas & - & - & - & - & + & + & - & - \\
\hline 4 & Flavanones & - & - & + & + & + & + & - & - \\
\hline 5 & Flavonols & - & - & - & - & - & - & - & - \\
\hline 6 & Saponins & + & + & - & - & - & - & - & - \\
\hline 7 & Alkaloids & + & + & - & + & + & + & + & + \\
\hline & Steroids & + & + & - & - & - & - & - & - \\
\hline
\end{tabular}

(+) positive; (-) negative. 
Seaweeds possess a range of chemical elements required by humans, such as calcium, sodium, magnesium, potassium, phosphorus, iodine, iron, and zinc. However, the quality and quantity may differ among individuals, species, habitats, maturity, and environmental conditions ${ }^{47}$. In fact, the semiquantitative analysis in present study revealed a different percentage of elements in the samples evaluated, even within the same group of seaweeds (Table 3). For instance, within the group of Rhodophyta J. adhaerens presented $85.27 \%(\mathrm{Ca}), 1.62 \%(\mathrm{Cl}), 7.54 \%$ (Si) while G. salicornia presented $6.26 \%(\mathrm{Ca}), 51.60 \%(\mathrm{Cl}), 0.84 \%(\mathrm{Si})$, respectively. In a study by El-Din and Al-Ahwany ${ }^{2}$, the sequence of the most common elements was $\mathrm{Ca}, \mathrm{Mg}$, $\mathrm{Na}$, followed by $\mathrm{K}$, in all three species analysed. Ito and Hori ${ }^{47}$ analysed different species of seaweeds, and also revealed that $\mathrm{Ca}, \mathrm{Mg}$ and $\mathrm{K}$ were the most common elements; where $\mathrm{K}$ was present in high proportion in Phaeophyta species: Padina arborescens, Hizikia fusiforme, and Sargassum thunbergii), Ca was in high proportion also in Phaeophyta (Scytosiphon lomentaria and Sargassum tortile), while $\mathrm{Mg}$ was in high proportion in
Chlorophyta (Ulva conglobata, Ulva pertusa and Enteromorpha compressa). Results from the present study also show high proportion of $\mathrm{Ca}$, in some seaweed such as $H$. cuneata and J. adherensis (72.04\% and 85.27\%), and in $\mathrm{K}$ in seaweeds such as $D$. suhrii, $G$. salicornia and $H$. rosea (28.50\%, 35.84\% and 38.36\%). Low atomic weight elements including $\mathrm{H}, \mathrm{C}, \mathrm{N}, \mathrm{Na}$ and $\mathrm{Mg}$ were not evaluated in our analysis, due to instrumental limitations (EDX-7000). The notable results in our analysis were referent to $\mathrm{Cl}$ which was in high proportion in three species analysed namely $P$. devriesii, G. salicornia and $H$. rosea $(51.05 \%, 51.60 \%$ and $40.51 \%$, respectively). The level of $\mathrm{Cl}$ may indicate that these species may be used as potential antibiotics. According to $\mathrm{Kim}^{48}, \mathrm{Cl}$ is the most common disinfectant. Therefore, the seaweed identified with high proportion of chlorine may be potential agent to be incorporated in antimicrobial products. The less represented elements such as Copper, Manganese, and Zirconium, were below $0.05 \%$, in most dried samples of seaweeds; Zinc and Chromium did not exceed $0.02 \%$ in all dried samples analysed in this study.

Table 3: Concentration of chemical elements in dried samples of eight species of seaweeds from Inhaca Island. ChloroChlorophyta, Phaeo-Phaeophyta, Rhodo-Rhodophyta.

\begin{tabular}{|c|c|c|c|c|c|c|c|c|c|}
\hline & & \multicolumn{3}{|c|}{ Chloro. } & \multirow{2}{*}{ Phaeo. } & \multicolumn{4}{|c|}{ Rhodo. } \\
\hline & & 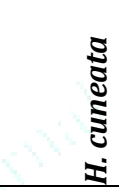 & 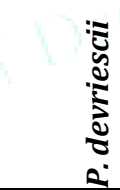 & 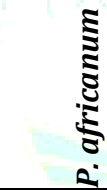 & & 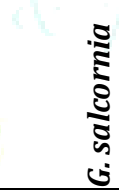 & 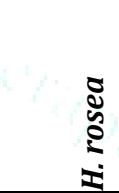 & 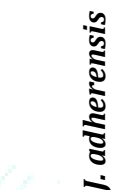 & 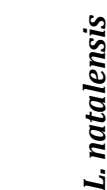 \\
\hline 1 & $\mathrm{Ca}$ & 72.038 & 13.63 & 4.474 & 27.077 & 6.263 & 8.045 & 85.272 & 26.528 \\
\hline 2 & $\mathrm{Cl}$ & 10.758 & 51.053 & 3.644 & 25.015 & 51.595 & 40.51 & 1.623 & 28.114 \\
\hline 3 & $\mathrm{Si}$ & 5.904 & 3.881 & 5.561 & 7.331 & 0.838 & 3.063 & 7.539 & 9.066 \\
\hline 4 & S & 3.959 & 12.739 & 5.645 & 9.941 & n.d & 7.503 & 1.395 & 10.742 \\
\hline 5 & $\mathrm{Fe}$ & 2.413 & 1.879 & 1.821 & 1.037 & 0.37 & 1.164 & 1.467 & 1.641 \\
\hline 6 & $\mathrm{Sr}$ & 1.513 & 0.207 & 0.033 & 0.202 & 0.044 & 0.051 & 0.593 & 0.212 \\
\hline 7 & $\mathrm{Br}$ & 1.353 & n.d & n.d & n.d & 0.29 & n.d & n.d & n.d \\
\hline 8 & K & 0.937 & 3.327 & 1.568 & 28.498 & 35.837 & 38.362 & 1.598 & 19.109 \\
\hline 9 & $\mathrm{Ti}$ & 0.423 & n.d & 0.119 & 0.139 & 0.048 & 0.309 & 0.203 & 0.283 \\
\hline 10 & $\mathrm{Cu}$ & 0.062 & 0.107 & 0.032 & 0.045 & 0.028 & 0.037 & 0.053 & 0.053 \\
\hline 11 & $\mathrm{Mn}$ & 0.035 & n.d & 0.025 & 0.084 & 0.013 & 0.043 & 0.046 & 0.034 \\
\hline 12 & $\mathrm{Zn}$ & 0.01 & 0.016 & 0.01 & 0.006 & 0.003 & 0.006 & 0.005 & 0.009 \\
\hline 13 & $\mathrm{Ba}$ & n.d & 2.774 & 0.274 & 0.397 & n.d & 0.385 & 0.207 & 3.437 \\
\hline 14 & $\mathrm{Cr}$ & n.d & n.d & 0.012 & n.d & n.d & n.d & n.d & n.d \\
\hline 15 & I & n.d & 1.652 & n.d & n.d & 0.391 & n.d & n.d & 0.625 \\
\hline 16 & $\mathrm{P}$ & n.d & 0.175 & 0.057 & 0.153 & 0.329 & 0.395 & n.d & 0.007 \\
\hline 17 & $\mathrm{Rb}$ & n.d & n.d & n.d & 0.014 & 0.02 & 0.01 & n.d & n.d \\
\hline 18 & $\mathrm{Ru}$ & n.d & 0.683 & n.d & n.d & n.d & n.d & n.d & n.d \\
\hline 19 & $\mathrm{Zr}$ & n.d & 0.032 & 0.014 & 0.049 & 0.004 & 0.086 & n.d & 0.131 \\
\hline
\end{tabular}

n.d - not detected.

To the best of our knowledge, this is one of the first studies carried out on wider methanolic extracts of seaweed species from Mozambique. A total of 82 phytocompounds were identified, where $P$. devriesii and L. natalensis showed more phytocompounds. Phytol and Z-8-Methyl-9-tetradecenoic were commonly present in all of the extracts, while sterols Campesterol, Cholest-5-en-3-ol 24-propylidene-(3.beta), Ethyl Oleate and gamma-Sitosterol were only found in $H$. cuneata and Padyna devriesii. Further colorimetric analysis revealed existence of phytocompound such as condensed tannins, alkaloids, coumarins, saponins in selected seaweed species. However, hydrolyzable tannin and flavonols tests were negatives in all eight species investigated. The semiquantitative analysis of chemical elements showed to be variable among the seaweeds species. The elements such as $\mathrm{Ca}, \mathrm{Cl}$ and $\mathrm{K}$ were present in high concentration in some of 
the seaweeds analysed. From this observation, seaweeds with high concentration of chlorine will be investigated for their potential use as antibiotic, as this element is the most common in disinfectants. Indeed, while this study highlights wider qualitative or semi-quantitative analysis it could support additional studies to emphasize the role of seaweeds in potential new drugs or healthy food.

\section{Acknowledgements}

This work was funded by WIO-RISE (Western Indian Ocean Region Initiative in Science and Education), SIDA (Swedish International Development Cooperation Agency) and UEM (University of Eduardo Mondlane). The authors would like to thank the Department of Biological Science and the Department of Chemistry at UEM for technical support. Our grateful goes to Mr Amós Nhaca for the field and laboratorial assistance.

\section{REFERENCES}

1. Agatonovic-Kustrin S, Morton DW. Cosmeceuticals Derived from Bioactive Substances Found in Marine Algae. Oceanography, 2013; 1:106. doi:10.4172/23322632.1000106.

2. El-Din SM, El-Ahwany AMD. Bioactivity and phytochemical constituents of marine red seaweeds (Jania rubens, Corallina mediterranea and Pterocladia capillacea). Journal of Taibah University for Science, 2016; 10:471-484.

3. Blunt JW, Copp BR, Hu WP, Munro MH, Northcote PT, Prinsep MR. Marine natural products. Natural Product Research, 2007; 24:31-86. doi:10.1039/b603047.

4. Pérez MJ, Falqué E, Domínguez H. Antimicrobial Action of Compounds from Marine Seaweed. Marine Drugs, 2016; 14, 52; 10.3390/md14030052.

5. Taskin E, Ozturk M, Taskin E, Kurt O. Antibacterial activities of some Marine algae from the Aegean sea (Turkey). African Journal of Biotechnology, 2007; 6:2746-2751.

6. Melpha Y, Manchu N, James JE. Phytochemical evaluation of two brown seaweeds from Muttom and Rasthacaud coasts of Tamil Nadu, India. Journal of Chemical and Pharmaceutical Research, 2014; 6:566-569.

7. Gullón B, Gagaoua M, Barba FJ, Gullón P, Zhang W, Lorenzo JM. Seaweeds as promising resource of bioactive compounds: Overview of novel extraction strategies and design of tailored meat products. Trends in Food Science \& Technology, 2020; 100:1-18.

8. Cox S, Abu-Ghannam N, Gupta S. Effect of Processing Conditions On Phytochemical Constituents Of Edible Irish Seaweed Himanthalia Elongata. Journal of Food Processing And Preservation, 2011; 36:348-363.

9. Marimuthu J, Antonisamy, Essakimuthu P, Narayanan J, Anantham B, Tharmaraj RJJM, Arumugam. Phytochemical characterization of brown seaweed Sargassum wightii. Asian Pacific Journal of Tropical Disease, 2012; 2:S109-S113.

10. Mansuya P, Aruna P, Sridhar S, Kumar J, Babu S. Antibacterial Activity and Qualitative Phytochemical Analysis of Selected Seaweeds from Gulf of Mannar Region. Journal of Experimental Sciences, 2010; 1:23-26.

11. Osman MEH, Aboshady AM, Elshobary ME. Production and characterization of antimicrobial active substance from some macroalgae collected from Abu- Qir bay (Alexandria) Egypt. African Journal of Biotechnology, 2013; 12:6847-6858.

12. Shanmugam J, Devi RK, Viswanathan $\mathrm{S}$, Nallamuthu $\mathrm{T}$. Antibacterial and antioxidant activity of red seaweeds from Kilakarai, Rameswaram, Tamilnadu, India. Journal of Pharmaceutical and Biomedical Sciences, 2013; 32:13861395.

13. Tanniou A, Vandanjon L, Incera M, Serrano-Leon E, Husa V. Assessment of the spatial variability of phenolic contents and associated bioactivities in the invasive alga Sargassum muticum sampled along its European range from Norway to Portugal. Journal of Applied Phycology, 2014; 2:1215-1230.

14. Bandeira SO. Seaweed resources of Mozambique. In: The Seaweed Resources of the World (Eds) Critchley AT; Ohno M, Japan International Cooperation Agency (JICA). 1998, 403408.
15. De Clercket O, Bolton JJ, Anderson RJ, Coppejans E. Guide to the seaweeds of KwaZulu-Natal, Scripta Botanica Belgica. 2005, 33. i-283.

16. Coppejans E; Richmond MD; Clerck O; Rabesandratona R. Marine Macroalgae. Seaweeds. In: MD Richmond (ed) A Guide to the seashores of eastern Africa and the western Indian Ocean Islands. Sida. 1997, 70-97.

17. Critchley AT, Aken ME, Bandeira SO, Kalk M. A revised list of marine algae from Inhaca Island, Mozambique. South African Journal of Botany, 1994; 37:261-265.

18. Isaac WE. Some Marine Algae from Xai-Xai, South African Journal of Botany, 1957; 23:75-102.

19. Massingue AO, Bandeira SO. Distribution of Seagrasses and Common Seaweeds around Nampula Province (Northern Mozambique) with emphasis to Mozambique Island. Western Indian Ocean Journal of Marine Science, 2005; 4:175-183.

20. Bandeira SO, António CM, Critchley AT. A taxonomic listing, including new distribution records, for benthic, intertidal seaweeds from Mecúfi, northern Mozambique. South African Journal of Botany, 2001; 67:492-496.

21. Carvalho AM, Bandeira SO. Seaweed flora of Quirimbas Archipelago, northern Mozambique. In: Chapman ARO, Anderson RJ, Vreeland VJ and Davison IR (eds). Proceedings of the XVIIth International Seaweed Symposium, Cape Town, South Africa. 2003. Oxford University Press. ISBN 019850742 9.

22. Critchley AT, Aken ME, Bandeira SO, Kalk M. A revised list of marine algae from Inhaca Island, Mozambique. South African Journal of Botany, 1997; 63:426-435.

23. Richmond MD. A guide to the Seashore of Eastern Africa and the Western Indian Ocean Islands. Wiomsa. 2010. p 464.

24. Abirami RG, Kowsalya S. Cosmeceuticals Derived from Bioactive Substances Found in Marine Algae. International Research Journal of Microbiology, 2012; 3:328-332.

25. Sitko R, Zawisza B. Quantification in X-Ray Fluorescence Spectrometry, X-Ray Spectroscopy. IntechOpen, 2012; doi: $10.5772 / 29367$.

26. Noda T, Tsuda S, Mori M, Takigawa S, Matsuura-Endo C, Kim S. Determination of the phosphorus content in potato starch using an energy-dispersive X-ray fluorescence method. Food Chemistry, 2006; 95:632-637.

27. Deyab M, Elkatony T, Ward F. Qualitative and Quantitative Analysis of Phytochemical Studies on Brown Seaweed, Dictyota dichotoma. International Journal of Engineering Development and Research, 2016; 4:674-678.

28. Yogeswari S, Ramalakshmi S, Neelavathy R, Johnpaul M. Identification and Comparative Studies of Different Volatile Fractions from Monochaetia kansensis by GCMS. The Global Journal of Pharmacology, 2012; 6:65-71.

29. Garg K, Shrivastava B, Bhargava A. GC-MS Analysis of Methanol and Ethyl Acetate Extract of fruits of Sphaeranthus indicus. Journal of Drug Delivery and Therapeutics, 2019; 9:28-30.

30. Domettila C, Joselin J, Jeeva S. Phytochemical analysis on some south Indian seaweeds. Journal of Chemical and Pharmaceutical Research, 2013; 5: 275-278.

31. Nandagopalan V, Gritto MJ, Doss A. GC-MS analysis of bioactive components of the methanol extract of Hibiscus tiliaceus Linn. Asian Journal of Plant Science and Research, 2015; 5:6-10.

32. Aziz S, Jafarah N, Yusof B, Zetty Z. Phytol-containing seaweed extracts as control for Ganoderma boninense. Journal of oil palm research, 2019; 31: 238-247.

33. Kalsoom R, Haider MS, Chohan C. Phytochemical analysis and antifungal activity of some medicinal plants against Alternaria specie isolated from onion. Journal of Animal and Plant Sciences, 2020; 30:1-7.

34. Femi-Adepoju A, Fatoba PO, Adepoju A, Oluyori AP Phytochemical analysis, antimicrobial activity and identification of phytoconstituents in Gleichenia pectinata (Willd.) C. Presl. International Journal of Biomedical and Advance Research, 2018; 9:400-406.

35. Egbung E, Anosike C, Utu-Baku A, Ogar I, Nna V. Phytochemical evaluation and GC-MS analysis of Hyptis verticillata cultivated in Calabar Cross River State, Nigeria. International Journal of Biological and Chemical Sciences, 2018; 11:2548-2559. 
36. Kebelmann K, Hornung A, Karsten U, Griffiths G. Thermochemical behaviour and chemical product formation from Polar seaweeds during intermediate pyrolysis. Journal of Analytical and Applied Pyrolysis, 2013; 104:131-138.

37. Mou Y, Meng J, Fu X. Antimicrobial and antioxidant activities and effect of 1 -hexadecene addition on palmarumycin $\mathrm{C} 2$ and C3 yields in liquid culture of endophytic fungus Berkleasmium sp. Dzf12. Molecules, 2013; 18:15587-15599.

38. Ogbe R. A Review of Dietary Phytosterols: Their occurences, metabolism and health benefits. Asian Journal of Plant Science and Research, 2015; 5:10 - 21.

39. Lopes G, Sousa C, Valentão P, Andrade PB. Sterols in Algae and Health. In Bioactive Compounds from Marine Foods (eds Hernández-Ledesma B, Herrero M). 2013, DOI:10.1002/9781118412893.ch9.

40. Choi JM, Lee E0, Lee HJ. Identification of campesterol from Chrysanthemum coronarium $\mathrm{L}$. and its antiangiogenic activities. Phytotherapy Research, 2007; 21:954-959. doi:10.1002/ptr.2189.

41. Bakar K, Mohamad H, Latip J, Seng T; Herng M. Fatty acids compositions of Sargassum granuliferum and Dictyota dichotoma and their anti-fouling activities. Journal of Sustainability Science and Management, 2017; 12:8 - 16
42. Pereira H, Barreira L, Figueiredo F. Polyunsaturated Fatty acids of marine macroalgae: potential for nutritional and pharmaceutical applications. Marine Drugs, 2012; 10:19201935.

43. Cowan MM. Plant Products as Antimicrobial Agents. Clinical Microbiology, 1999; 12:564-582.

44. Desai S, Desai DG, Kaur H. Saponins and their biological activities. Pharma Times, 2009; 41:13-16.

45. Okwu DE. Improving the Nutritive Value of Cassava Tapioca Mea with Local Spices. Journal of Nutraceuticals, Functional \& Medical Foods, 2001; 3:43-50.

46. Jeeva S, Domettila C, Anantham B, Mahesh M. Preliminary phytochemical studies on some selected seaweeds from Gulf of Mannar, India. Asian Pacific Journal of Tropical Biomedicine, 2012; 2:S30-S33.

47. Ito K, Hori K. Seaweed: Chemical composition and potential food uses. Food Reviews International, 1989; 5:101-144.

48. Kim J, Pitts B, Stewart P, Camper A, Yoon J. Comparison of the Antimicrobial Effects of Chlorine, Silver Ion, and Tobramycin on Biofilm. Antimicrobial agents and chemotherapy, 2008; 52:1446-1453. 